\title{
Metaphor as the refection of culture determined cognition
}

\author{
Lyubov A. KOZLOVA \\ Altai State Pedagogical University \\ Barnaul, Russia
}

\begin{abstract}
The article belongs to the cognitive dimension of contemporary cognitive linguistics based on the idea that the processes of the world conceptualization take place in the context of a certain culture and language imparting culturally determined character to our cognition. The ethnocultural specificity of cognition has various forms of manifestation in language, the most explicit of which is metaphor because the very nature of our thinking is metaphorical and reflects the correspondence with experience which is also culture-specific. The study aims to investigate how culturally determined cognition finds its manifestation in metaphor. The main goal of the article is to point out and characterize the forms of manifestation of ethnocultural specificity of metaphor in the text. The analysis is based on a corpus of 860 metaphorical expressions obtained from 34 English-language fiction texts. The main methods of analysis are conceptual, comparative-culturological and contextual analyses. The introduction contains a short survey of theoretical works related to the interaction of language, cognition and culture and describes the way methods are applied. In the second part the author analyses the interrelations between three branches of linguistics: ethnolinguistics, linguoculturology, and cultural linguistics united on the basis of their interest in the study of language in the cultural aspect. The main body of the article presents the analysis of metaphor in the aspect of culture specific cognition which results in the identification of three forms of representing the culturally determined cognition in metaphor: 1) the degree of metaphorical density of the text and the manner of metaphorical representation from the perspective of explicitness/implicitness; 2) the specificity of conceptual spheres which serve as the source of metaphors; 3 ) the choice of objects of metaphorical description determined by the sociocultural conventions of a linguocultural society. By way of conclusion, the author outlines the prospects of metaphor studies in the aspect of culture specific cognition.
\end{abstract}

Keywords: ethnolonguistics, cultural linguistics, cognitive-cultural approach, metaphor, culture determined cognition

\section{For citation:}

Kozlova, Lyubov A. 2020. Metaphor as the refection of culture determined cognition. Russian Journal of Linguistics 24 (4). 899-925. DOI: 10.22363/2687-0088-2020-24-4-899-925 
Научная статья

\title{
Метафора как отражение этнокультурной детерминированности когниции
}

\author{
Л.А. КОЗЛОВА \\ Алтайский государственный педагогический университет \\ Россия, Барнаул
}

\begin{abstract}
Аннотация
Статья относится к исследованиям в области когнитивно-культурологического направления, в основе которого лежит тезис о том, что познание мира осуществляется в контексте определенной культуры и языка, придающим когниции культурно-детерминированный характер. Этнокультурная детерминированность когниции находит множественные формы манифестации в языке, но наиболее полное отражение она находит в метафоре, поскольку процесс нашего мышления метафоричен в своей основе и базируется на соответствиях в опыте, который является культурно-специфичным. Объектом исследования является метафора, а предметом - отражение в ней культурной детерминированности когниции. Цель статьи выделить и описать формы манифестации культурно-обусловленной специфики метафоры в тексте. Материалом исследования послужил корпус из 860 примеров, отобранных из 34 англоязычных художественных текстов. Основными методами исследования являются концептуальный, сопоставительный лингвокультурологический и контекстологический анализ. Во введении дается краткий экскурс в историю изучения вопросов взаимодействия языка, сознания и культуры, представлена информация о материале и методах исследования. Во втором разделе рассматривается соотношение между тремя направлениями лингвистики: этнолингвистикой, лингвокультурологией и культурологической лингвистикой, отмечается общность реализуемого в них подхода к анализу языка и излагаются теоретические основания изучения метафоры в когнитивно-культурологическом ракурсе. В основной части работы проводится анализ корпуса фактического материала, в результате которого выделяются три формы манифестации этнокультурной детерминированности когниции в метафоре: 1) степень метафорической насыщенности текста и характер представления метафоры по признаку эксплицитности/имплицитности; 2) специфика концептуальных областей, служащих сферой-источником метафор; 3) выбор объектов метафорического описания в соответствии с конвенциями определенной культуры. В заключительной части статьи обозначены направления, по которым может быть продолжено изучение метафоры в когнитивно-культурологическом ракурсе.
\end{abstract}

Ключевые слова: этнолингвистика, культурологическая лингвистика, когнитивно-культурологический подход, метафора, этнокультурная детерминированность когниции

\section{Для цитирования:}

Козлова Л.А. Метафора как отражение этнокультурной детерминированности когниции. Russian Journal of Linguistics. 2020. T. 24. № 4. C. 899-925. DOI: 10.22363/2687-0088-202024-4-899-925

\section{1. Введение: постановка проблемы. Материал и методы исследования}

Вопрос о тесной взаимосвязи и взаимовлиянии языка, сознания и культуры существует столько, сколько существует наука о языке, но в разные периоды развития лингвистики ему отводилось разное место, что определялось теми главными задачами, которые ставились перед лингвистикой в контексте 
доминирующих парадигм научного знания. В контексте т.н. традиционной лингвистики, охватывающей несколько веков и объединявшей различные направления, в силу ее антропоцентрической направленности этим вопросам уделялось значительное внимание. Наиболее последовательно мысль о сущности языка как отражения мировидения нации развивалась в трудах В. фон Гумбольдта, утверждавшего, что «каждый язык вбирает в себя нечто от конкретного своеобразия своей нации и в свою очередь действует на нее в этом же направлении» (Гумбольдт 2000: 166).

Э. Сепир, указывая на роль языка в сохранении всех «мыслимых разновидностей нашего опыта», подчеркивал, что язык может служить «символическим руководством к пониманию культуры» (Сепир 1993: 261-262). В.В. Виноградов, развивая идеи отечественных лингвистов И.И. Давыдова, А.А Потебни и др., считал, что описание словарного состава языка не может быть полным без обращения к знаниям о культуре его носителей. Изучение языка А.С. Пушкина позволило ему высказать мысль о том, что широкое распространение французского языка оказало большое влияние не только на русский язык, но и на русское мышление и культуру (Виноградов 2000).

В рамках структурной, системоцентрической в своей основе научной парадигмы, занимавшей доминирующее положение в лингвистике на протяжении почти всего XX века и ставившей своей основной задачей описание внутреннего устройства языка, вопросы взаимодействия языка и культуры находились на периферии предметного поля лингвистики. Но вместе с тем $\Phi$. де Соссюр не отрицал важности изучения языка в широком социо- и этнокультурном контексте, считая это основной задачей т.н. внешней лингвистики, которая, по его мнению, должна была стать дальнейшей ступенью развития лингвистической науки (Соссюр 1977: 53-55).

Развитие когнитивной лингвистики, антропоцентрической в своей основе, закономерно привело к ее активному сотрудничеству с другими науками, объектом которых является человек и его история, его психология, географическая, социальная и культурная среда его проживания - все те факторы, совокупность знаний о которых образует когнитивный контекст, оказывающий влияние на наше сознание и находящий репрезентацию в языке. Как отмечал В.А. Виноградов, когниция человека всегда культурнообусловлена, и когнитивной основой классификации является этнокультурная категоризация мира (Виноградов 2000: 420).

Отмечая тесную взаимосвязь и взаимообусловленность языка, сознания и культуры, Д.Г. Эверетт представляет ее в виде формулы: “The formula that summarizes my own concept of language is: Cognition + Culture + Communication = Language. This means that each normal human being has a brain, belongs to a community with values, and needs to communicate, and the confluence of these states results in a language” (Everett 2012: 35). Смысл этой формулы можно интерпретировать следующим образом: каждый человек наделен интеллектом, является членом общества с определенными культурными ценностями и 
испытывает потребность в коммуникации, и совокупность этих составляющих лежит в основе языка.

Этнокультурная детерминированность когниции находит множественные формы манифестации в языке: в его словарном составе, фразеологическом фонде, в грамматическом строе, в особенностях построения текста и дискурса, в этностиле коммуникации, а также в метафоре. Объектом изучения нашей статьи является метафора, а предметом - отражение в ней культурной детерминированности когниции. Целью статьи является выделение и описание форм манифестации культурно-обусловленной специфики метафоры в тексте.

Базовым методологическим положением, лежащим в основе когнитивнокультурологического подхода, реализуемого в статье, является тезис о том, что процессы концептуализации и интерпретации мира осуществляются в контексте определенной культуры и языка, что придает когниции культурнодетерминированный характер. Основу проведенного исследования составляет следующая гипотеза: этнокультурная обусловленность когниции находит свое наиболее полное отражение в метафоре, поскольку процесс нашего мышления метафоричен в своей основе и основан на соответствиях в опыте, который также является культурно-специфичным. При этом этнокультурная специфика метафоры может иметь различные формы своей манифестации в тексте.

Материалом исследования является корпус примеров общим количеством 860, отобранных из 34 англоязычных художественных текстов объемом около 10 тысяч страниц. Корпус англоязычных художественных текстов включает произведения британских, американских, канадских и австралийских авторов, представляющих т.н. Anglo culture, а также произведения писателей-билингвов, в текстах которых находят отражение культурные ценности и образы сознания таких культур, как ближневосточная, японская, китайская, южноафриканская и русская. Методология исследования складывается из комплекса методов, включающих концептуальный анализ, используемый при выявлении и описании концептуальных областей источника и цели, участвующих в процессах метафоризации; сопоставительный лингвокультурологический анализ, направленный на выявление факторов культурологического характера, обусловливающих выбор концептов, служащих источником и целью, а также контекстологический анализ, используемый при интерпретации смысла метафорических высказываний.

\section{2. Сущность метафоры в когнитивно-культурологическом ракурсе}

\section{1. Этнолингвистика, лингвокультурология и культурологическая лингвистика как направления, реализующие когнитивно-культурологический подход к исследованию языка}

В настоящее время сложилось несколько направлений, занимающихся исследованием языка в аспекте его тесной взаимосвязи с культурой. К числу 
таких направлений относится этнолингвистика, лингвокультурология и культурологическая лингвистика. Несмотря на различия в их названии, между этими направлениями, на наш взгляд, существует гораздо больше общности, чем различий. Остановимся кратко на характеристике этих направлений, выделяя преимущественно не столько различия между этими направлениями, сколько то общее, что их объединяет. Безусловный приоритет в исследовании вопросов взаимодействия языка и культуры принадлежит, на наш взгляд, Анне Вежбицкой, в работах которой получили разработку этносинтаксис, этнопрагматика и этносемантика (Wierzbicka 1992, Wierzbicka 2003 (1991), Wierzbicka (2006), Wierzbicka 2010).

Этнолингвистические исследования Анны Вежбицкой и ее последователей (Enfield 2013, Goddard 2004, Goddard 2006) нашли широкий отклик в европейской и особенно в российской лингвистической науке. Как отмечает Е.В. Падучева, влияние работ Вежбицкой на лингвистику в России было намного значительнее, чем в других странах, причиной чего является не только славянская близость, но и созвучность лингвистических идей, развиваемых в российской науке, тем вопросам, которые ставит А. Вежбицкая в своих трудах (Падучева 1996: 23-26). Идеи Вежбицкой нашли свое дальнейшее развитие в исследованиях российских лингвистов, выполненных на материале различных языков и посвященных этнокультурной обусловленности словарного состава языка (Беляевская 2007, Зализняк, Левонтина, Шмелев 2005, 2012 и др.), фразеологического фонда (Добровольский 1997, Телия 1996, Зыкова 2015 и др.), грамматического строя (Богданова 2018, Гак 2000, Козлова 2012, 2018 и др.), текста и дискурса (Бочегова 2003, Иванова, Чанышева 2018, Ларина, Озюменко 2017 и др.), речевых актов и этностиля коммуникации (Беляева-Станден 2004, Ларина 2007, 2009, Larina 2015 и др.), проблем межкультурной коммуникации (Ларина 2017, Тер-Минасова 2000 и др.).

Вопросы взаимодействия языка, сознания и культуры в европейской лингвистической науке, во многом под влиянием работ А. Вежбицкой и ее школы, рассматриваются в направлении, именуемом этнолингвистика, которая сегодня включает такие разделы, как этносинтаксис, этнопрагматика, этнофразеология (Bartmiński 2017 и др.). При этом следует отметить, что использование термина этнолингвистика и его смысловое содержание во многом определяются традицией и направлением исследований, сложившихся в той или иной научной школе (Кабакова 1993: 112). Так, в отечественной традиции термин этнолингвистика изначально использовался преимущественно в отношении работ, посвященных изучению языковых явлений в историческом ракурсе, а материалом нередко служили фольклорные и мифологические тексты, религиозные обряды, суеверия, приметы и т.д. Такое направление этнолингвистических исследований было характерно для работ многих российских ученых (Толстой 1995 и др.)., чьи исследования были направлены на реконструкцию фрагментов архаической картины мира, 
нашедших отражение в русском языке. Очевидно, именно первоначальная диахроническая ориентация этнолингвистических исследований в отечественной лингвистике послужила стимулом для формирования и стремительного развития направления, получившего название лингвокультурология, которое было ориентировано на изучение процессов взаимодействия современного языка и культуры. Как отмечала С.В. Иванова, лингвокультурология - это не что иное, как «современное развитие идей этнолингвистики, дополнившее этнолингвистику с ее сосредоточенностью на диахронических фактах данными из области исследования синхронических процессов» (Иванова 2004: 40). В то же время она признает «диссипативный» характер самого термина. Этнолингвистические исследования в других странах не ограничены только перечисленными аспектами, а имеют более широкий диапазон, и их материалом являются не только древние и фольклорные, но также и современные тексты. Сегодня попытка разграничения этнолингвистики и лингвокультурологии по принципу диахронической или синхронической направленности представляется не вполне оправданной, так как этот принцип не находит отражения в названиях наук и не имеет параллелей в исследованиях, проводимых в других странах. Заметим, что сам термин лингвокультурология не имеет широкого распространения в метаязыке зарубежных лингвистов, занимающихся вопросами изучения взаимодействия языка и культуры, что, на наш взгляд, затрудняет научную коммуникацию «поверх границ культур».

Сложившаяся практика изучения вопросов взаимодействия языка и культуры в лингвокультурологии такова, что одни работы больше тяготеют к лингвистике, другие - к культурологии, третьи - представляют собой своеобразный синтез того и другого. А поскольку к лингвокультурологии относят исследования как лингвистического, так и культурологического плана, она представляет собой более широкую область исследования,

Как отмечает Н.Н. Болдырев, культурологический подход к исследованию языка может включать несколько направлений:

1) изучение языка как элемента культуры;

2) изучение культурно- и национально-специфических концептов на основе анализа языковых данных;

3) изучение национальной специфики языковых значений и механизмов формирования смыслов в рамках определенной культуры;

4) изучение языка как средства межкультурной коммуникации, в том числе перевода как одного из средств коммуникации (Болдырев 2018: 423).

По мнению Н.Н. Болдырева, первые два направления ориентированы в большей степени на области философии, социологии, общей семиотики, собственно культурологии, и их рассмотрение требует разработки специальных методов культурологического анализа и, соответственно, целью таких исследований должно быть изучение культуры, традиций, культурных ценностей и т.д., в той или иной мере связанных с языком. Третье и четвертое 
направление связаны с анализом специфики формирования языковых значений и смыслов в контексте определенной культуры и относятся к сфере лингвистики (Болдырев 2018: 423-424).

В американской лингвистической науке направление, занимающееся изучением языка в культурологическом ракурсе, получило название cultural linguistics. Основателем данного направления является американский исследователь Г. Палмер, который обозначил этим термином область исследований, сформировавшуюся на основе синтеза лингвистической антропологии, этносемантики и этнографии коммуникации. В основе концепции, представленной в работе Г. Палмера, лежит тезис о том, что язык представляет собой «игру вербальных символов, основанных на образности» ("language is the play of verbal symbols that are based in imagery”) (Palmer 1996: 4). Образность при этом понимается Г. Палмером в самом широком смысле как результат восприятия действительности с помощью всех сенсорных каналов и его последующая ментальная обработка, т.е. концептуализация, в результате которой в нашем сознании формируется и хранится в различных формах широкий инвентарь культурно детерминированных ментальных образов, включающих когнитивные модели, схемы, сценарии, фреймы и другие форматы знания (Palmer 1996: 290).

По мере развития данного направления и под влиянием идей когнитивизма культурологическая лингвистика вошла в более широкое предметное поле когнитивно-ориентированных исследований, что нашло отражение в замене некоторых терминов, используемых Г. Палмером. Так, в работах недавно ушедшего от нас австралийского исследователя Ф. Шарифиана, активно занимавшегося проблемами культурологической лингвистики и их прикладным потенциалом, вместо термина образность (imagery) используется термин cultural conceptualization (Sharifian 2011, 2012). Как он отмечал в одной из своих программных работ, культурологическая лингвистика занимается исследованием процессов концептуализации, которые являются культурно-обусловленными, кодируются и находят свое проявление в естественном языке (Sharifian 2017: 33), а предложенный им подход широко используется при изучении таких явлений, как варианты английского языка, процессы метафоризации, дискурсивный анализ, межкультурная коммуникация (Sharifian 2017: 42-53, Sharifian, Palmer 2007). В этой связи хотелось бы отметить неточность в переводе на русский язык отдельных англоязычных терминов, используемых в метаязыке культурологической лингвистики. Так, термин cultural conceptualization нередко переводится как культурная концептуализация (Дехнич 2018: 121), что, в силу многозначности русского прилагательного культурный неизменно вызывает в сознании антонимическое сочетание некультурная концептуализация. Очевидно, более точным русским эквивалентом термина cultural conceptualization является культурнообусловленная концептуализация.

Вместе с тем, как показывает анализ работ в области этнолингвистики, лингвокультурологии и культурологической лингвистики, несмотря на 
различия в терминологии и объеме изучаемых явлений, исследователи, работающие в перечисленных направлениях, едины во мнении о том, что наша когниция культурно детерминирована, а язык, сознание и культура тесно взаимосвязаны и должны изучаться с учетом этой взаимосвязи. Представляется возможным говорить о том, что основанием для объединения этнолингвистики, лингвокультурологии (в той ее части, объектом которой является язык) и культурологической лингвистики может служить общность их подхода к анализу языковых фактов, который является когнитивно-культурологическим в своей основе. При этом, как подчеркивает Н.Н. Болдырев, в пользу такого мнения говорит тот факт, что большинство культурологических работ опираются на терминологию и методологию когнитивной лингвистики, что и дает основание считать когнитивно-культурологическое направление одним из направлений когнитивной лингвистики (Болдырев 2018: 425).

\section{2. Этнокультурная обусловленность когниции и ее манифестация в метафоре}

Как мы уже отмечали выше, этнокультурная обусловленность процессов концептуализации и интерпретации мира находит свою манифестацию в широком круге языковых явлений и процессов: в фонетическом строе, лексиконе, фразеологии, грамматическом строе, построении текста и дискурса, в этностиле коммуникации. Но наиболее полное отражение этнокультурная обусловленность когниции находит в метафоре, поскольку процесс нашего мышления, как показала работа Дж. Лакоффа и М. Джонсона, метафоричен в своей сущности, будучи основанным на телесном опыте взаимодействия с миром, получаемом через все каналы восприятия. Суть концептуальной метафоры, как ее представили Дж. Лакофф и М. Джонсон, заключается в способности думать об одной сфере в терминах другой, что полностью соответствует основному закону когнитивного развития: познавать новое, опираясь при этом на уже известное, познанное в процессе взаимодействия с действительностью на основе полимодальности восприятия и служащее базой-источником в процессах метафоризации (Lakoff, Johnson 1980). Такая трактовка сущности метафоры убедительно продемонстрировала мнение о том, что использование метафор не является исключительно уделом поэтов, политиков и других категорий людей, стремящихся к образному выражению своих мыслей, а носит повсеместный характер, являясь строительным материалом мысли, сознания и коммуникации.

Основное положение когнитивного подхода к сущности метафоры, гласящее, что наше мышление метафорично в своей основе, расширило границы изучения данного явления, привлекая внимание не только к словесным, но и иным средствам репрезентации концептуальной метафоры: музыкаль-

ным, художественным, паравербальным и артефактным метафорам, что позволяет составить представление о том, как работают другие, невербальные формы мышления. Будучи универсальным когнитивным механизмом, 
метафора находит воплощение не только в слове, но и в других семиотических системах: в жестах, ритуалах, поступках, артефактах, архитектуре, живописи, музыке и моде. Отметим при этом, что изучение метафорических отношений в других семиотических системах не означает потерю интереса к словесной метафоре и ее экспрессивному потенциалу. Так, исследование стилистических приемов метафоры и сравнения в когнитивном ракурсе убедительно показывает, что в их глубинной основе лежит единый механизм, а различие заключается только в том, что признак сходства, лежащий в их основе, в сравнении находит эксплицитное выражение, а в метафоре он лишь имплицируется, что подтверждает аристотелевское определение метафоры как скрытого сравнения.

Дальнейшим развитием теории концептуальной метафоры явилась теория концептуальной интеграции, которая показала креативный, динамический характер процесса смыслопорождения вообще и метафоризации в частности (Turner, Fauconnier 1995, Sweetser, Fauconnier 1996, Fauconnier, Turner 1998), что имеет большое значение для исследования оригинальных, авторских метафор, позволяющих раскрыть креативный потенциал языковой личности и проникнуть в специфику художественного мышления.

Накопление опыта познания мира и формирование на этой основе концептуальной системы всегда проходит в определенных географических, климатических, социальных, экономических, психологических и иных условиях, на основе которых проходит формирование культуры лингвокультурного сообщества, включающей традиции, ценности, стереотипы поведения, ритуалы и т.д. Совокупность всех этих условий формирует концептуальную систему, привнося в картину мира этническую окраску, сквозь призму которой идет дальнейшее познание мира, что неминуемо придает своеобразие метафорическому мышлению. Этот тезис лежит в основании следующего этапа в развитии когнитивного подхода к изучению метафоры, который является когнитивно-культурологическим по своей сути. Еще в 1997 году, обсуждая возможные перспективы в исследовании процессов метафоризации, ученые высказывали мнение о том, что будущее метафорологии лежит в области изучения процессов взаимосвязи языка и культуры (Steen \& Gibbs 1997: 6). Как показывают многочисленные работы последних десятилетий в области метафорологии (Будаев 2007, Будаев 2011, Стоянова 2013, Будаев, Чудинов 2020, Deignan 2003, Kövecses 2005, Kövecses 2010, Musolff 2007, Musolff 2019, Yu 2018 и др.), вопросы взаимодействия языка и культуры, сочетания универсального и культурно-специфического в метафоре действительно находятся в фокусе внимания многих исследователей. Остановимся кратко на некоторых из этих исследований, представляющих для нас особый теоретический интерес. Так, в своем исследовании, посвященном изучению метафоры в культурологическом ракурсе, 3. Ковечес представляет результаты сопоставительного анализа анкет американских и венгерских студентов, которым было предложено ответить на вопрос: что такое жизнь? Ведущей метафорой 
в ответах американских студентов была метафора путешествия (Life is a journey), в своих анкетах студенты что акцентируют такие аспекты жизни, как постоянное движение, стремление к достижению конечной цели, а в большинстве ответах венгерских студентов жизнь описывается как битва, в которой надо побеждать, преодолевать трудности. Проведенный им сопоставительный анализ показывает, как исторический опыт страны, политические и экономические условия жизни влияют на выбор области-источника для метафорического описания области-цели (Kövecses 2005: 84-85).

В работах А. Музолфа (Musolff 2004, 2019 и др.) убедительно показано взаимодействие универсального и культурно-специфического в процессах метафоризации. На примере анализа использования концепта СЕРДЦЕ в качестве области-источника в немецком и британском политическом дискурсе ученый показывает, что метафора, основанная на общей области-источнике, выражает при этом принципиально разные смыслы, в которых содержится оценка роли этих стран в деятельности Евросоюза. Отводя своим странам ведущую роль в деятельности Евросоюза и называя их сердцем Европы, немецкие и британские авторы используют при этом разные ассоциативные признаки концепта СЕРДЦЕ. В немецком дискурсе в основе данной метафоры лежит ориентационный признак - географическое положение Германии в центре Европы, что и служит основой для метафорического использования слова сердце. В основе употребления этой же метафоры в британском политическом дискурсе лежит не ориентационный, а функциональный признак: подобно тому, какую важную функцию выполняет сердце в нашем организме, Британия, по мнению англичан, выполняла такую же важную функцию в Европейском Союзе (Musolff 2004: 61-68).

Продолжая свои исследования в области метафорологии на основе анализа корпусных данных и результатов анкетирования респондентов, представляющих разные культуры (Musolff 2019), А. Музолф делает два вывода, представляющие, на наш взгляд, значительный теоретический интерес для дальнейшего изучения метафоры в когнитивно-культурологическом ракурсе. На основе анализа корпусных данных автор демонстрирует способность так называемых мертвых, или спящих метафор (dead, or sleeping metaphors) к активации, приобретению новых семантико-прагматических коннотаций, приводящих к модификации первоначальных смыслов, что показывает непрерывность процессов метафоризации. Анализ анкет респондентов, представляющих разные лингвокультурные сообщества, убедительно показывает роль социального опыта, культурных ценностей и идеалов в интерпретации смысла метафорических выражений. Результаты анкетирования позволили автору затронуть еще один важный аспект в изучении креативного потенциала метафоры. Как подчеркивает автор, процесс интерпретации метафор может быть не менее креативным, чем процесс их порождения, что, можно полагать, обусловлено диалогическим характером нашего мышления, о чем писал М.М. Бахтин. 
В работе профессора Пенсильванского университета Нин Ю (Ning 2018) на примере анализа метафоры LIFE IS AN OPERA, характерной для китайской культуры, получил убедительное подтверждение тезис о культурной обусловленности когниции. Автор показывает, что метафора LIFE IS A PLAY, ставшая конвенциональной для всей европейской культуры и нашедшая словесное воплощение в знаменитой шекспировской фразе "All the world is a stage", во многом обусловлена тем фактом, что основной формой представления в европейской культуре была пьеса. В китайской культуре данная метафора получила модификацию и формулируется как LIFE IS AN OPERA, что во многом обусловлено тем, что прототипом сценического представления в китайской культуре служит пекинская опера. Автор представляет подробный анализ концепта OPERA, имеющего сложную структуру и включающего целый комплекс компонентов, отражающих специфику традиционной пекинской оперы: либретто, постановка, музыка, исполнительское мастерство, телодвижения, оркестр, сцена, закулисье, реакция зрителей и т.д., каждый из которых может стать источником для метафорического представления различных событий и феноменов современной жизни в Китае, что и определяет ключевой статус данной метафоры в китайской культуре.

Анализ этих и других работ, посвященных этнокультурной специфике метафоры, позволяет заключить, что когнитивной основой процессов метафоризации является соответствие в опыте, обусловливающее способность нашего сознания концептуализировать одну сущность на основе ее аналогии с другой, освоенной в результате опыта взаимодействия с миром. А поскольку накопление этого опыта всегда осуществляется в рамках определенной культуры, процесс метафоризации всегда оказывается в той или иной мере культурно-обусловленным.

Следует признать, что в большинстве исследований, посвященных национально-культурной специфике метафоры, в фокусе внимания чаще всего оказываются концептуальные области источника метафоры, что находит отражение в терминологии: антропоморфная, зооморфная, метафора родства и т.д. Мы полагаем, что культурно-специфичный компонент оказывает влияние не только на выбор области-источника метафоры, но и на выбор области-цели, а также на метафорическую насыщенность текста и характер представления метафоры по признаку эксплицитности/имплицитности, что мы попытаемся показать в ходе анализа эмпирического материала.

\section{3. Формы манифестации культурно-специфического в метафоре. Результаты анализа эмпирического материала}

Как показал анализ фактического материала, формы манифестации национально-культурной специфики метафоры могут быть различными. Прежде всего, обладая большим эмоциональным и экспрессивным потенциалом, метафора вносит значительный вклад в формирование этностиля коммуникации. Так, например, коммуникативный стиль народов Ближнего Востока 
отличается повышенной степенью экспрессивности и эмоциональности, что кардинально отличает его от английского и американского коммуникативного стиля. Именно высокая степень эмоциональности и экспрессивности обусловливают высокую метафоричность коммуникативного стиля языков Ближнего Востока, на что указывают многие исследователи. А. Рибани, этнический сириец, эмигрировавший в США в молодом возрасте, сопоставляя англоязычный и сирийский коммуникативные стили, отмечал, что арабы считают английскую речь слишком педантичной и прозаичной, а представители англоязычной культуры находят речь арабов излишне высокопарной и эмоциональной, что нередко приводит к взаимному неудовольствию при общении. По мнению арабов, основной характеристикой речи должна быть поэзия, а не прозаическая точность (Poetry, and not prosaic accuracy, must be the dominant feature of speech). Давая характеристику ближневосточной речи, Рибани пишет:

"Just as the Oriental loves to flavour his food strongly and to dress in bright colours, so is he fond of metaphor, exaggeration and positiveness in speech" (Подобно тому, как представитель Востока любит обильно приправлять свою пищу пряностями, одеваться в яркие цвета, свою речь он также любит приправлять метафорой, преувеличением и позитивностью ${ }^{1}$ ) (цитируется по: (Wierzbicka 2006: 27). Поэтому естественно ожидать, что тексты представителей этих культур отличаются высокой степенью метафоричности, что соответствует нормам ближневосточного этностиля. Для подтверждения сказанного обратимся к примерам из романов современного афганского писателя Халеда Хоссейни, ныне живущего в США и пишущего на английском языке

(1) When Mariam thought of this baby, her heart swelled inside of her. It swelled and swelled until all the loss, all the grief, all the loneliness and selfabasement of her life washed away (Kh. Hosseini. A Thousand Splendid Suns). (2) I loved him in that moment, loved him more than I'd ever loved anyone, and I wanted to tell them all that I was the snake in the grass, the monster of the lake (Kh. Hosseini. The Kite Runner).

(3) Mariam lay on the couch, hands tucked between her knees, watched the whirlpool of snow twisting and spinning outside the window. She remembered Nana saying once that each snowflake was a sigh heaved by an aggrieved woman somewhere in the world. That all the sighs drifted up the sky, gathered into clouds, then broke into tiny pieces that fell silently on the people below. As a reminder of how women like us suffer, she'd said. How quietly we endure all that falls upon us (Kh. Hosseini. A Thousand Splendid Suns).

(4) He's a boy, you see, and, as such, what does he care about reputation? But you? The reputation of a girl, especially one as pretty as you, is a delicate thing, Laila. Like a mynah bird in your hands. Slacken your grip and away it flies (Kh. Hosseini. A Thousand Splendid Suns).

\footnotetext{
1 Здесь и далее перевод наш. - Л.К.
} 
(5) The wells ran even lower and the river dried, unlike Baba Ayub's anguish, a river that swelled and swelled with each passing day (Kh. Hosseini. And the Mountains Echoed).

И хотя романы написаны на английском языке, автор стремится сохранить стиль ближневосточной культуры, уделяя особое внимание передаче эмоционального состояния своих героев и используя в качестве области-источника те образы сознания, которые были сформированы на базе родной культуры (like a mynah bird - пример № 4).

Полной противоположностью ближневосточной культурной традиции являются культурные нормы британского общества, предписывающие сдержанность в проявлении эмоций. Как известно, одним из ключевых слов британской культуры является cool reason (здравый cмысл), отражающий основной принцип поведения в обществе - опора на здравый смысл и умеренность в проявлении эмоций. По словам К. Фокс, сдержанность (moderation) является одним из компонентов концепта ENGLISHNESS и означает стремление избегать экстремальности, излишеств и интенсивности в поведении, суждениях и проявлении эмоций (Fox 2014: 551). Проявление сдержанности в выражении эмоций связано с уважением к личному пространству и продиктовано принципом вежливости, которая воспитывается у англичан с раннего детства. Подтверждением сказанному может служить следующий отрывок из романа Яна Макьюэна «Atonement», в котором описывается поведение мальчиков-близнецов, испытывающих сильное эмоциональное потрясение и пытающихся скрыть свои чувства, следуя правилам вежливости, принятом в их обществе.

(6) They stood about and Jackson said, 'I don't like it here'. The simplicity of the remark unhinged his brother who went by a wall and found something of interest in the skirting board which he worried with the tip of his shoe.

Lola put her arm across his shoulder and said: 'We' ll be going home soon'. Her arm was much thinner than his mother's and Pierrot began to sob, but quietly, still mindful of being in a strange house where politeness was all (I. McEwan. Atonement).

Нормы британской культуры предписывают сдержанность в проявлении эмоций даже в минуты скорби. Так, в следующем отрывке героиня рассказывает о том, что во время траурной церемонии она с ужасом осознает, что в глазах у нее наворачиваются слезы, и она отворачивается, чтобы скрыть это от окружающих. Тот факт, что это было замечено, вызывает у нее недовольство собой, поскольку это противоречит принятым в ее культуре нормам поведения.

(7) 'What a lovely guy, eh?' Raymond said, somewhat redundantly. I found, to my extreme consternation, that nascent tears were forming in my eyes, and I turned away to rub them before they could spill over. Annoyingly, Raymond, usually the least observant of men, had noticed (G. Honeyman. Eleanor Oliphant is Completely Fine). 
Характерным для понимания отношения англичан к проявлению эмоций является следующий короткий отрывок из романа А. Мердок. Описывая состояние своего героя в момент чрезвычайного эмоционального напряжения, автор пишет:

(8) Huge emotions were working inside me and I was concentrated on keeping calm, staring at a motionless misty willow, at a seagull on a post (I. Murdoch. A Word Child).

Вместо подробного описания переполняющих его эмоций персонаж сообщает о том, как он пытался их сдержать. Данная культурная норма не могла не повлиять на частотность использования метафор в передаче эмоций, которая, как показывают наблюдения, значительно ниже, чем, например, в русской лингвокультуре. Англичане скорее расскажут об эмоциональном состоянии другого человека, чем о своем собственном, что находит свое отражение в художественном тексте: метафоры эмоций гораздо чаще встречаются в авторском повествовании, чем в прямой или внутренней речи героев. Для русской культуры, в которой горячее сердце имеет гораздо большую ценность, чем здравый смысл (именно на этой черте русского характера основан призыв «Голосуй сердием»), более характерно метафорическое представление эмоций, даже воспевание эмоций, особенно эмоций грусти, печали и горя, например: «Горе ты горе, - соленое море! Ты и накормишь, ты и напоишь, ты и закружишь, ты и обслужишь!» (М. Цветаева). Зулейха не могла удержать боль внутри, и боль выплеснулась, затопила все вокруг блескучую ангарскую воду, малахит берегов и холмов, утес, на котором стоит Зулейха, небосвод в белой пене облаков (Г. Яхина. Зулейха открывает глаза).

Этнокультурная обусловленность метафоры находит свое отражение и в способах ее представления в тексте в плане ее эксплицитности/имплицитности. Если для ближневосточного этностиля более характерно эксплицитное выражение метафорических смыслов, как было показано в приведенных выше примерах, то для японской лингвокультуры, отличающейся высокой степенью контекстной зависимости, более характерны имплицитные метафоры, для экспликации смысла которых требуется знание японского культурного контекста. Так, в предисловии к своему роману “An Artist of the Floating World” Казуо Исигуро пишет, что это - «самый японский из всех его романов». Хотя этот роман, как и все романы Казуо Исигуро, написан на английском языке, автор пишет в предисловии, что он стремился к тому, чтобы роман воспринимался читателями как перевод с японского. Для создания подобного эффекта он иногда буквально переводил японские выражения на английский язык для того, чтобы за английскими предложениями читатель мог почувствовать особенности японского этностиля с присущей ему недосказанностью, имплицитностью представления смысла. Роман открывается следующим предложением: 
(9) If on a sunny day you climb the steep path from the little wooden bridge still referred to as 'The Bridge of Hesitation', you will not have to walk far before the roof of my house becomes visible between the tops of two gingko trees (K. Ishiguro. An Artist of the Floating World).

Если читатель не знает о том, что гингко билоба - дерево, существующее на земле на протяжении 300 миллионов лет и считающееся в Японии символом стойкости и долголетия, было первым растением, которое вернулось к жизни после взрыва атомной бомбы в Хиросиме, он не заметит имплицитного смысла данной артефактной в своей основе метафоры, которая является ключевой для всего романа, поскольку именно она передает доминантный смысл романа, повествующего о стойкости японской нации и трудном процессе ее восстановления после Второй мировой войны. Для японского читателя, знающего историю и культуру своей страны, данная метафора является достаточно понятной, а для представителя другой культуры, незнакомого с этим национальным символом, скрытый смысл данной метафоры может так и остаться незамеченным.

Следует признать, что наши наблюдения о степени метафорической насыщенности текста как показателе культурной специфики метафоры носят лишь предварительный характер, поскольку, во-первых, для повышения валидности таких выводов необходим сопоставительный количественный анализ метафор из текстов, написанных на разных языках, а, во-вторых, тем фактом, что метафорическая насыщенность текста обусловлена не только принадлежностью автора к той или иной культуре, но и особенностями его идиостиля.

Вторым способом манифестации этнокультурной детерминированности когниции являются те образы сознания, которые служат областьюисточником метафоры. Такие факторы, как географические и климатические условия проживания, реалии высокой и бытовой культуры, принадлежность к той или иной религии, запечатленные в памяти и образах сознания, служат областью-источником метафор, окрашивая их в национально-специфические цвета. Так, особенности английского климата находят свое отражение в частотности использования образа дождя и ассоциативно связанных с ним образов в метафорике языка: Ср. ср. русское Нет худа без добра и английское Ever cloud has a silver lining; русское Будь что будет и английское Rain or shine. Примечательно, что в русской паремии Будь что будет находит свое отражение специфика мировосприятия русских, вера в неизбежность судьбы, случая. Представитель русской культуры откладывает сбережения на черный день, а англичанин - на дождливылй (a rainy day). Метафора дождя нашла свое косвенное отражение (в результате принципа метафорической аттракции, в соответствии с которым центральный образ метафоры втягивает в свою сферу связанные с ним образы) и в таком лингвистическом термине, как umbrella term (зонтиковый термин), которым определяется междисциплинарный характер когнитивной лингвистики. И в русском, и в английском языках 
преодоление трудностей в жизни, сопротивление обстоятельствам ассоциируется с образом человека, преодолевающего водную стихию, но тот факт, что в русском сознании водное пространство ассоциируется прежде всего с рекой, а в английском - с морем, находит свое отражение в варьировании исходной метафоры: в русском языке - пльтьь против течения (реки), в английском - to swim against the tide (против морского прилива).

Как показывает анализ фактического материала, наибольшей частотностью в англоязычной культуре обладает морская метафора, включающая широкий спектр образов сознания, связанных с океаном, морем, его обитателями, водными средствами передвижения, артефактами и видами деятельности, связанными с морем, и т.д.

(10) It was also that he'd dined at her home the previous night and if they wanted to keep matters on an even keel, then it was his turn to provide a meal for her (E. George. Careless in Red).

(11) But this admiral was a rare bird: always wanting to know what was going on at the docks, mediating in disputes, testing the political waters, questioning everything, missing nothing (J. Moyes. The Ship of Brides).

(12) Canada, being a cultural backwater, had not been swept away by the wave of Freudianism that washed over the United States in the fifties (M. Atwood. Great Unexpectations).

При этом образы водной стихии и морские суда часто персонифицируются:

(13) Oh blessed Northern Sea, a real sea with clean merciful tides... (I. Murdoch. The Sea, the Sea).

(14) The sea ran up the beach, indifferent and careless (Elizabeth Buchan. Revenge of the Middle-Aged Woman)

(15) Captain George Highfield was much given to fanciful thinking, but as he walked along the dry dock, staring up through the sea mist at the hulls of Victoria and her neighbours, he often allowed himself to think about the vessels as his fellows. Hard not to see them as suffering some kind of hurt, as having some kind of personality when they had allied themselves to you, given you their all, braved high seas and fierce fire (J. Moyes. The Ship of Brides).

Морская метафора используется для описания различных объектов авторского описания в тексте:

(16) I tell her about all the little sounds and smells and colours and lights and advertising and people and fashions and newspaper headlines that make up the noisy ocean of Tokyo (R. Ozeki. A Tale for the Time Being).

(17) He was an anomaly, a sport, a deviation from the mean. 'Fries his fish in a different pan' was the way people sometimes described him on the island (R.Ozeki. A Tale for the Time Being).

Примеры (16), (17) взяты из романа американской писательницы японского происхождения Рут Озеки “A Tale for the Time Being”, действие 
которого происходит в Британской Колумбии и Японии. Как показал анализ текста, в образах сознания, служащих сферой-источником большинства метафор, нашли свое отражение островное положение места действия, океан и его обитатели. Автор использует метафоры, созданные на основе этих образов, для описания атмосферы Токио (пример 16), для передачи характера нестандартной личности (пример 17).

При описании судьбы японской девочки в качестве ключевой метафоры романа автор использует образ рыбы, который многократно повторяется в тексте романа, реализуя при этом разные метафорические значения: ускользания смысла (пример 17), страха (пример 18), отваги, смелости (пример 19).

(17) In Japan some words have kotodama which are spirits that live inside a word and give it a special power. The kotodama of NOW felt like a slippery fish, a slick fat tuna (R. Ozeki. A Tale for the Time Being).

(18) There was this weight in my stomach like a big cold fish dying just below my heart... (R. Ozeki. A Tale for the Time Being)

(19) So I walked into school that first day back, my heart was pounding, but the fish in my stomach felt strong and powerful (R. Ozeki. A Tale for the Time Being).

Образ рыбы в животе является традиционным в японской культуре: в японском языке существует большая группа метафор гнева, сферой-источником которых служит концепт HARA (живот), имеющий важное значение для японской культуры (Matsuki 1995). Можно полагать, что значимость данного образа для японской культуры и его роль в передаче смысловой доминанты романа послужили основанием для использования данного образа в качестве заглавия при переводе романа на русский язык, хотя, несомненно, этот выбор продиктован и чрезвычайной трудностью перевода оригинального заглавия “ A Tale for the Time Being”, в котором реализуются два значения сочетания the time being: временное существо u for the time being - пока, на время.

Национально-культурная специфика образов сознания наиболее четко выявляется при сопоставлении разных способов выражения одного и того же смысла, например, при сравнении способов выражения множества в разных культурах. Так, в англоязычной культуре наиболее частотным метафорическим средством выражения значения множества служит образ моря или океана.

(20) I saw what he meant as we left the orchard behind us and entered an ocean of olive trees (Peter Mayle. A Good Year).

(21) ...the American gangster would still have a vast ocean of dollars to launder (F. Forsyth. Avenger).

(22) I gave up on the "light sandwich lunch" almost straightaway. At least, I briefly tried sawing away at two loaves of bread - and ended up with huge, wonky slices, each one more misshapen than the last, lying in a sea of crumbs (S. Kinsella. The Undomestic Goddess). 
В русскоязычном сознании образ множества ассоциируется не только с морем или океаном (океан эмоций, море улыбок, море иветов), но также и с такими реалиями, как лес (лес рук), куча (куча забот), тьма (тьма проблем), менее характерными для англоязычного сознания. Примечательно, что использование образа леса в качестве источника метафоры в английском языке акцентирует не столько значение множества, сколько значение плотности объектов в пространстве:

(23) I sat high on the seat in an empty carriage, and in fading daylight watched as the train slid past office blocks and out into the forests of council flats and snaking terrace houses of Vauxhall and Clapham (B. Bryson. Notes from a Small Island).

Иные географические, климатические и другие условия проживания того или иного лингвокультурного сообщества формируют иную базу-источник метафорических образов.

(24) Without the Thursday interludes the week is as featureless as a desert

(J.M. Coetzee. Disgrace).

Так описывает состояние своего персонажа южноафриканский писатель Дж. М. Кутзее (ныне гражданин Австралии) в своем романе "Disgrace”, используя при этом образ пустыни, что представляется вполне естественным, поскольку доминирующее положение в картине мира жителей африканского континента занимает именно этот образ.

В качестве сферы-источника для передачи значения множества могут служить и другие реалии культуры, как в следующем примере, в котором основой для передачи множественности послужил американский топоним Manhattan.

(25) Gary turned on the light and surveyed the Manhattan of books before him (S. Fry. The Liar).

Особый интерес для исследования этнокультурной специфики метафоры представляют собой тексты писателей-билингвов, в языковой картине мира которых сосуществуют как образы, сформированные на основе родной культуры, так и новые образы, формирующиеся в процессе усвоения новой культуры. Синкретизм языкового сознания билингва, совмещение в нем образов сознания взаимодействующих языков может находить отражение в тех метафорах, которые создаются в процессе речемыслительной деятельности билингва на новом языке. Описывая область-цель, билингв может использовать в качестве источника образы, сформированные на основе родного языка. В качестве примера приведем отрывок из романа американской писательницы китайского происхождения Эми Тэн.

(26) When I saw the hills, I laughed and shuddered at the same time. The peaks looked like giant fried fish heads trying to jump out of a vat of oil. Behind each hill, I could see shadows of another fish, and then another and another (Amy Tan. The Joy Luck Club). 
В данном примере источником для сравнения, в основе которого, как мы отмечали, лежит тот же когнитивный механизм, что и у метафоры, служит традиционное блюдо китайской кухни.

При этом вполне естественен тот факт, что образы сознания, базирующиеся на основе чувственного, эмоционального опыта родной культуры, оказываются достаточно прочными и могут оживляться при освоении нового опыта. Так, И. Бродский в своем венецианском эссе, написанном на английском языке, использует для передачи значения множества образ Кремля:

(27) On the red plush divans, around a small marble table with a kremlin of drinks and teapots on it, sat Wystan Auden (I. Brodsky. Watermark).

В. Набоков, который признавался в одном из интервью, что «его английский - всего лишь эхо его русского», при описании внешности женщины использует в качестве источника метафоры традиционный для русского фольклора образ русалки:

(28) Pnin, then a rising scholar and she, a more limpid mermaid than now but practically the same person, had met around 1925, in Paris (V. Nabokov. Pnin).

Третий способ манифестации культурно-специфического в метафоре находит свое выражение в том, что, подобно области-источнику, объект метафорического описания (область-цель) также имеет значительную национально-культурную специфику. Как показывает сопоставительный анализ, в разных культурах прослеживаются четкие различия в выборе объектов метафорического описания. Хорошо известная всему миру любовь французов к хорошему вину и хорошей пище находит отражение в языке, что позволяет характеризовать французский язык как the language of gastronomy. Английский писатель Питер Мейл, который, как пишут в аннотациях к его книгам, “eats, drinks, writes and lives in Provence”, отмечал, что французы говорят о еде с такой же страстью, с какой представители других культур говорят о политике или спорте, и выразил это в афористической форме:

(29) The religion of the French is food. And wine, of course (P. Mayle. A Year in Provence).

Рассмотрим примеры метафорического описания гастрономических объектов, представленных в произведениях П. Мэйла. Так, рассказывая о своем посещении обеда в семье француза, автор торжественно описывает сцену появления тележки с нагруженными на нее блюдами праздничного обеда, используя для этого фразу «праздник, который всегда с тобой» (a movable feast), которая отсылает нас к известному роману Э. Хемингуэя с таким же названием, но в данном случае речь идет о празднике не столько для души, сколько для желудка:

(30) And then, with a rumble of wheels, the Roussels' daughter, a more delicate version of her mother, emerged from the house with a movable feast- 
a trolley laden with slices of fat-dappled sausage, wedges of pizza, tapenade of squares of toasted bread, slivers of raw vegetables with an anchoiade dip, olives both green and black, radishes with white butter, and a thick earthenware terrine of thrush pâté, with the unfortunate bird's beak protruding from the dark meat (P. Mayle. A Good Year).

Ритуал принятия пищи, открывания бутылки вина нередко метафорически описывается как некое театральное представление:

(31) The sommelier returned, and Charlie paused to watch him perform the opening ceremony (P. Mayle. A Good Year).

Особое отношение французов к пище находит свое выражение и в том, что, подобно тому, как англичане персонифицируют водную стихию, французы так же часто персонифицируют пищу. Например:

(33) Many of the wines are old and tired (P. Mayle. A Good Year).

(34) His face became serious as he stared into the dark red heart of his wine (P. Mayle. A Good Year).

Хорошо известен и тот факт, что романтические отношения имеют не менее важное значение во французской культуре, чем еда, что позволяет характеризовать французский язык не только как the language of gastronomy, но и как the language of romance (Deutscher 2010: 2). Такая тесная взаимосвязь концептуальных областей ЕДА и ЛЮБОВЬ находит свое языковое воплощение в том, что гастрономические изыски нередко метафорически описываются языком романтических отношений в таких терминах, как passionate, love at first sight, lasting love affair, а романтические - в гастрономических терминах, т.е. область-источник и область-цель метафоры могут меняться местами.

Культурные нормы и традиции лингвокультурного сообщества во многом определяют выбор тех областей цели, которые становятся или, напротив, исключаются из объектов метафорического осмысления в той или иной культуре. Весьма характерной в этом плане является область интимных отношений. Проблемы секса и связанных с ним эмоций достаточно широко обсуждаются в рамках американской и некоторых западных культур (например, датской). В традиционной русской культуре, а также в большинстве восточных культур интимные отношения, как правило, не являются объектом подробного описания в тексте. Этот факт обусловливает широкое распространение метафор для описания данной области-цели в американской культуре и, напротив, их ограниченное употребление в русской культуре. Таким образом, особенности культуры оказывают влияние не только на выбор областиисточника метафоры, но и на выбор области-цели метафорического описания.

\section{4. Заключение}

В основу проведенного исследования, выполненного с позиции когнитивно-культурологического подхода, положен тезис об этнокультурной 
детерминированности когниции и множестве способов ее манифестации в языке. Выдвинув гипотезу о том, что этнокультурная обусловленность когниции находит свое наиболее полное отражение в метафоре, используя при этом различные формы своей манифестации в тексте, мы ставили своей задачей выявление и описание этих форм. Анализ значительного корпуса фактического материала, проведенного с использованием комплекса методов исследования, включающих концептуальный, сопоставительный лингвокультурологический и контекстологический виды анализа, позволил выявить и охарактеризовать три основные формы манифестации культурно-специфического в метафоре: степень метафорической насыщенности текста и способ репрезентации метафоры в аспекте эксплицитности/имплицитности; этнокультурная специфика образов сознания, служащих областью-источником метафор, а также выбор концептуальной сферы-цели метафоры, обусловленный традиционными культурными ценностями, характерными для того или иного лингвокультурного сообщества.

Заключая, отметим, что в статье лишь частично освещен такой важный аспект этнокультурной специфики метафоры, как специфика метафорического мышления билингвальной языковой личности, не рассмотрен вопрос о судьбе национально-специфических метафор при переводе. Эти и другие вопросы, связанные с изучением метафоры в когнитивно-культурологическом ракурсе, заслуживают подробного рассмотрения и тем самым очерчивают перспективы дальнейшей работы в этом направлении.

(C) Lyubov Kozlova, 2020
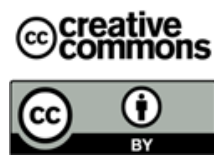

This work is licensed under a Creative Commons Attribution 4.0 International License https://creativecommons.org/licenses/by/4.0/

\section{СПИСОК ЛИТЕРАТУРЫ / REFERENCES}

Беляева-Станден Е.И. Межкультурная прагматика совета - русско-американский диалог: Почему ты меня все время критикуешь? Языковое сознание: теоретические и прикладные аспектыл. Москва; Барнаул: Изд-во Алт. ун-та, 2004. С. 305-319. [BelyavaStanden, Elena. 2004. Mezhkul'turnaya pragmatika soveta - russko-amerikanskij dialog: 'Pochemu ty menya vsyo vremya kritikuesh'? (Intercultural pragmatics of giving advice Russian-American Dialogue: "Why are you always critical of me"?) In Natalia Ufimtseva et al. (eds.), Yazykovoe soznanie: Teoreticheskie i prikladnye aspekty, 305-319. Moscow; Barnaul: Altai State University Pulishing.].

Беляевская Е.Г. Культурологическая информация в семантике языковых единиц Bопросы когнитивной лингвистики. 2007. № 4. C. 44-50. [Belyaevskaya, Elena. 2007. Kul'turologicheskaya informaciya $\mathrm{v}$ semantike yazykovyh edinic (Cultural information in natural language semantics). Issues of Cognitive Linguistics 4. 44-50].

Богданова Л.И. Оценочные смыслы в русской грамматике (на материале глаголов эмоционального отношения) Вестник РУДН. Серия: Лингвистика. Russian Journal of 
Linguistics. 2018. T. 22. № 4. C. 844-873. [Bogdanova, Ludmila. 2018. Evaluative senses in Russian grammar (on the basis of verbs of emotional attitude). Russian Journal of Linguistics 22 (4). 844-873.] DOI: 10.22363/2312-9182-2018-22-4-844-873.

Болдырев Н.Н. Язык и система знаний. Когнитивная теория языка. Москва: Издательский Дом ЯСК, 2018. [Boldirev, Nikolay. 2018. Language and the System of Knowledge. A Cognitive Theory of Language. Moscow: LRC Publishing house].

Бочегова Н.Н. Национально-культурная специфика художественного текста и способы ее выражения Studia Linguistica. Перспективные направления современной лингвистики. Вып. ХІІ. СПб.: РГПУ им. А.И. Герцена, 2003. С. 242-252. [Bochegova, Natalia. 2003. Nacional'no-kul'turnaya specifika hudozhestvennogo teksta i sposoby ee vyrazheniya (Ethnic cultural features in fiction texts end means of its rendering). Studia Linguistica. Perspektivnye napravleniya sovremennoj lingvistiki Vol. XII. 242-252. St. Petersburg, Herzen Russian State Pedagogical University].

Будаев Э.В. 2007. Политическая метафора в лингвокультурологическом аспекте. URL: https://cyberleninka.ru/article/n/politicheskaya-metafora-v-lingvokulturologicheskomaspekte (дата обращения: 06.05.2020). [Budaev, Eduard. 2007. Politicheskaya metafora $\mathrm{v}$ lingvokul'turologicheskom aspekte (Political metaphor in linguocultural aspect). URL: retrieved from: https://cyberleninka.ru/article/n/politicheskaya-metafora-vlingvokulturologicheskom-aspekte (accessed 06 May 2020)].

Будаев Э.В. Сопоставительная политическая метафорология. Автореф. дисс. ... д-ра филол. наук. Екатеринбург, 2010. [Budaev Eduard 2010. Sopostavitel'naya Politicheskaya Metaforologiya (Comparative Studies of Political Metaphor). Avtoref. ... d-ra filol. nauk. Ekaterinburg].

Будаев Э.В., Чудинов А.П. Современная российская политическая метафорология (2011-2020 гг.) Филологический класс. 2020. 25 (2). C. 103-113. [Budaev, Eduard \& Anatoly Chudinov. 2020. Contemporary Russian Political Metaphorology (2011-2020). Philological Class 25 (2). 103-113.] DOI: 10.26170/FK20-02-09.

Виноградов В.А. Классификационные типы в движении Res Linguistica: сборник статей к 60-летию профессора В.П. Нерознака. Москва: Academia, 1999. С. 420-423. [Vinogradov, Viktor. 1999. Klassifikacionnye tipy v dvizhenii (Classification types in movement). Res Linguistica: sbornik statej $k$ 60-letiyu professora V.P. Neroznaka, 420-423. Moscow: Academia].

Виноградов В.В. Язык Пушкина: Пушкин и история русского литературного языка. Москва: Наука, 2000. [Vinogradov, Viktor. 2000. Yazyk Pushkina: Pushkin i istoriya russkogo literaturnogo yazyka (The Language of Alexander Pushkin: Pushkin and the History of the Russian Literary Language). Moscow: Nauka].

Гак В.Г. Язык как форма самовыражения народа Язык как средство трансляции культуры. Москва: Наука, 2000. С. 54-68. [Gak, Vladimir. 2000. Yazyk kak forma samovyrazheniya naroda (Language as means of a nation's self-expressing). In M.B. Eschich et al. (eds.), Yazyk kak sredstvo translyacii kul'tury, 54-68. Moscow: Nauka].

Гумбольдт фон В. Избранные труды по языкознанию. Пер. с нем. под ред. и с предисл. д-ра филол. н., проф. Г.В. Рамишвили. 2-е изд. Москва: Прогресс, 2000. [Humboldt, Wilhelm, von. 2000. Izbrannye trudy po yazykoznaniyu (Selected Papers in Linguistics). In G.V. Ramishvili (eds.), Moscow: Progress].

Дехнич О.В. Культурная когниция и метафора: теоретические наброски западной теории Когнитивные исследования языка. Вып. XXXIV. Москва: МГУ имени М.В. Ломоносова: Неолит, 2018. С. 120-122. [Dekhnich, Olga. 2018. Cultural Cognition and Metaphor: Theoretical Sketches of Western Theory. Cognitive Studies of Language Vol. XXXIV. 120-122. Moscow Lomonosov State University]. 
Добровольский Д.О. Национально-культурная специфика во фразеологии Bonpocb языкознания. 1997. № 6. C. 37-48. [Dobrovol'skij, Dmitry. 1997. Nacional'no-kul'turnaya specifika vo frazeologii (Ethnic cultural peculiarities in phraseology). Voprosy yazykoznaniya 6. 37-48].

Зализняк А.А., Левонтина И.Б., Шмелев А.Д. Ключевые идеи русской языковой картины мира. Москва: Языки славянской культуры, 2005. [Zalizniak, Anna, Levontina, Irina \& Alexey Šmelev. 2005. Klyučevye idei russkoj jazikovoy kartiny mira (Key Ideas of the Russian Language Picture of the World]. Moscow: Jaziki slavyanskoy kul tury Publ.].

Зализняк А.А., Левонтина И.Б., Шмелев А.Д. Константы и переменные русской языковой картины мира: монография. Москва: Языки славянской культуры, 2012. [Zalizniak, Anna, Levontina, Irina \& Alexey Šmelev.2012. Konstanty I peremennye russkoj jazikovoy kartiny mira (Constants and Variables of the Russian Language Picture of the World). Moscow: Jaziki slavyanskoy kul tury Publ.].

Зыкова И.В. Концептосфера культуры и фразеология: Теория и методы лингвокультурологического изучения. Москва: Ленанд, 2015. [Zykova, Irina. 2015. Konceptosfera kul'tury $i$ frazeologiya: Teoriya $i$ metody lingvokul'turologicheskogo izucheniya (Conceptual Framework of Culture and Phraseology: Theory and Methodology of Theoretical Studies). Moscow: Lenand].

Иванова С.В. Лингвокультурология и лингвокогнитология: сопряжение парадигм. Уфа: РИО БашГУ, 2004. [Ivanova, Svetlana. 2004. Lingvokul'turologiya $i$ lingvokognitologiya: sopryazhenie paradigm (Cultural and Cognitive Linguistics: Blending of the Two Paradigms). Ufa: Bashkir State University Publ.].

Иванова С.В., Чанышева 3.3. Слово в контексте культурно-исторического универсума: на примере политического дискурса США Вестник Российского университета дружбы народов. Серия: Лингвистика. Russian Journal of Linguistics. 2018. Т. 22. № 4. C. 821-843. [Ivanova, Svetlana, \& Zulfira Chanysheva. 2018. Slovo v kontekste kulturno-istoricheskogo universuma: na primere politicheskogo diskursa SSHA (A Word in the context of a cultural and historical universe: Some case studies from the US political discourse). Russian Journal of Linguistics 22 (4). 821-843]. DOI: 22363/2312-9182-224-821-843.

Кабакова Г.И. Французская этнолингвистика: проблематика и методология Bonpocbl языкознания. 1993. № 6. С. 100-113. [Kabakova, Galina. 1993. Frantsuzskaya etnolingvistika: problematika i metodologiya (French ethnolinguistics: problems and methodology). Voprosy yazykoznaniya 66. 100-113].

Козлова Л.А. Этнокультурный потенциал грамматического строя языка и его реализация в грамматике говорящего: монография. Изд 2-е, испр. и доп. Барнаул: АлтГПА, 2012. [Kozlova, Lyubov. 2012. Etnokul'turnyj potencial grammaticheskogo stroya yazyka $i$ ego realizaciya $v$ grammatike govoryashchego (Ethnic cultural potential of the grammar of a language and its actualization in the speaker's grammar). Barnaul: Altai State Pedagogical Academy Publ.].

Козлова Л.А. Этнокультурный потенциал залоговых форм и его дискурсная актуализация Вестник Российского университета дружбы народов. Серия: Лингвистика. 2018. T. 22. № 4. C. 874-894. [Kozlova, Lyubov. 2018. The ethnocultural potential of voice forms and its discourse actualization. Russian Journal of Linguistics 22 (4). 874-894] DOI: 10.22363/2312-9182-2018-22-4-874-894.

Ларина Т.В. Этностилистика в ее коммуникативном аспекте Известия РАН. Серия литературы и языка. 2007. Т. 66. № 3. C. 3-17. [Larina, Tatiana. 2007. Etnostilistika v ee kommunikativnom aspekte (Ethnostylistics in communicative perspective). Bulletin of the Russian Academy of Sciences. Literature and Language 66 (3). 3-17]. 
Ларина Т.В. Категория вежливости и стиль коммуникации: сопоставление английских и русских лингвокультурных традииий. Москва: Языки славянских культур, 2009. [Larina, Tatiana. 2009. Kategoriya vezhlivosti $i$ stil' kommunikacii: sopostavlenie anglijskih $i$ russkih lingvokul'turnyh tradicij (Politeness and Communicative Styles: Comparison of English and Russian Culture Traditions). Moscow: Yazyki slavyanskih kul'tur Publ.].

Ларина Т.В. Основы межкультурной коммуникации: учебник для студ. учреждений высш. образования. Москва: Издательский центр «Академия», 2017. [Larina, Tatiana. 2017. Osnovy mezhkul'turnoj kommunikacii (Intercultural Communication). Moscow: Izdatel'skij centr «Akademiya»].

Ларина Т.В., Озюменко В.И. Свобода личности как конституирующий компонент английского дискурса. Известия Южного Федерального университета. Филологические науки. 2017. № 2. С. 160-172. [Larina, Tatiana \& Vladimir Ozyumenko. 2017. Personal freedom as a constitutive element of English discourse. Izvestiya Yuzhnogo Federal'nogo universiteta. Filologicheskie nauki 2. 160-172].

Падучева Е.В. Феномен Анны Вежбицкой // Вежбицкая А. Язык. Культура. Познание: Пер. с англ. Отв. ред. М. А. Кронгауз, вступ. ст. Е. В. Падучевой. Москва: Рvсские словари, 1996. С. 5-32. [Paducheva, Elena. 1996. Fenomen Anny Vezhbickoj. In Maksim Krongauz (eds.), A. Wierzbicka. Language. Culture. Cognition. Moscow: Russkie slovari].

Сепир Э. Избранные труды по языкознанию и культурологии. Пер. с англ. Москва: Прогресс-Универс, 1993. [Sapir, Edward. 1993. Izbrannye trudy po yazykoznaniyu $i$ kul'turologii (Selected Papers in Linguistics and Culture Studies). Moscow: ProgressUnivers].

Соссюр де Ф. Труды по языкознанию. Перевод с французского под редакцией А.А. Холодовича. Москва: Прогресс, 1977. [Saussure, Ferdinand, de. 1977. Trudy po yazykoznaniyu (Papers in Linguistics). Moscow: Progress Publ.].

Стоянова Е. Метафора сквозь призму лингвокультурной ситуаџии. Шумен: Университетско изд-во «Епископ Константин Преславски», 2013. [Stoyanova, Elena. 2013. Metafora skvoz' prizmu lingvokul'turnoj situacii (Metaphor in the Light of Linguocultural Context). Shumen: Universitetsko izd-vo «Episkop Konstantin Preslavski»].

Телия В.Н. Русская фразеология: семантический, прагматический и культурологический аспекты. Москва: Языки русской культуры, 1996. [Teliya, Veronika. 1996. Russkaya frazeologiya: semanticheskij, pragmaticheskij i kul'turologicheskij aspekty (Russian Phraseology: Semantic, Pragmatic and Cultural Aspects). Moscow: Yazyki russkoj kul'tury].

Тер-Минасова С.Г. Язык и межкультурная коммуникаџия. Москва: Слово, 2000. [Ter-Minasova, Svetlana. 2000. Yazyk i mezhkul'turnaya kommunikaciya (Language and Intercultural Communication). Moscow: Slovo Publ.].

Толстой Н.И. Язык и народная культура: Очерки по славянской мифологии и этнолингвистике. Москва: Индрик, 1995. [Tolstoj, Nikita. 1995. Yazyk i narodnaya kul'tura: Ocherki po slavyanskoj mifologii i etnolingvistike (Language and Folk Culture: Essays in Slavic Mythology and Ethnolinguistics). Moscow: Indrik Publ.].

Чудинов А.П. Россия в метафорическом зеркале: Когнитивное исследование политической метафоры (1991-2000): Монография. Екатеринбург: Урал. гос. пед. ун-т, 2001 [Chudinov, Anatoly. 2001. Rossiya v metaforicheskom zerkale: Kognitivnoe issledovanie politicheskoj metafory (1991-2000) (Russia in the Mirror of Metaphor: Cognitive Study of Political Metaphor). Ekaterinburg: Ural State Pedagogical Institute].

Bartmiński, Jerzy. 2017. Ethnolinguistics in the year of 2016. Etnolingwistyka 28. 9-31. DOI: 10.17951/et.2016.28.7. 
Deignan, Alice. 2003. Metaphorical expressions and culture: An indirect link. Metaphor and Symbol 18 (4). 255-271.

Deutscher, Guy. 2010. Through the Language Glass, Why the World Looks Different in Other Languages. New York: Metropolitan books, Henry Holt and Company.

Enfield, Nick, F. 2004. Ethnosyntax: Introduction. In Enfield, Nick, F (eds.), Ethnosyntax: explorations in grammar and culture, 1-30. Oxford: Oxford University Press.

Everett, Daniel L. 2013. Language - the Cultural Tool. London: Profile Books.

Fauconnier, Gilles \& Mark Turner. 1998. Conceptual integration networks. Cognitive Science 22. 133-187.

Fox, Kate. 2014. Watching the English. The Hidden Rules of English Behaviour. Londod.: Hodder \& Stoughton.

Goddard, Cliff. 2004. Ethnosyntax, ethnopragmatics, sign-functions, and culture. In Nick L. Enfield (eds.), Ethnosyntax. explorations in grammar and culture 52-73. Oxford: Oxford University Press.

Goddard, Cliff. 2006. Ethnopragmatics: a new paradigm: Ethnopragmatics. In Cliff Goddard (eds.), Understanding discourse in cultural context 1-20. Berlin: Mouton de Gruyter.

Kövecses, Zoltán. 2005. Metaphor in Culture. Universality and Variation. Cambridge: Cambridge University Press.

Kövecses, Zoltán. 2010. A new look at metaphorical creativity in cognitive linguistics. Cognitive Linguistics 21(4). 663-697.

Lakoff, George \& Mark Johnson. 1980. Metaphors We Live By. Chicago, Chicago University Press.

Larina, Tatiana. 2015. Culture-specific communicative styles as a framework for interpreting linguistic and cultural idiosyncrasies. International Review of Pragmatics. Special issue: Communicative styles and genres 7 (5). 195-215.

Matsuki, Keiko. 1995. Metaphors of anger in Japanese. In J. Taylor \& R.E. Maclaury (eds.), Language and the Cognitive Construal of the World, 137-151. Berlin: Mouton de Gruyter.

Musolff, Andreas. 2004. Metaphor and conceptual evolution. Metaphoric de 7. 55-75.

Musolff, Andreas. 2019. Creativity in Metaphor Interpretation. Russian Journal of Linguistics 23 (1). 23-39. DOI:10.22363/2312-9182-2019-23-1-23-39.

Palmer, Gary B. 1996. Toward a Theory of Cultural Linguistics. Austin: University of Texas Press.

Sharifian, Farzad. 2011. Cultural Conceptualizations and Language. Theoretical Framework and Applications. Amsterdam/Philadelphia: John Benjamins.

Sharifian, Farzad. 2012. Linguistic theory and cultural conceptualizations. Journal of Language, Culture, and Translation 1 (3). 93-110.

Sharifian, Farzad. 2017. Cultural linguistics Ethnolinguistic 28. 33-61. DOI: 10.17951/ et.2016.28.31.

Sharifian, Farzad F., \& Palmer, Gary B. (eds.). 2007. Applied Cultural Linguistics. Amsterdam: John Benjamins.

Steen, Gerald J. \& Gibbs, Raymond W. 1997. Introduction. In Gerald D. Steen \& Raymond W. Gibbs (eds.), Metaphor in cognitive linguistics. Selected papers from the fifth international cognitive linguistics conference, 1-8. Amsterdam/Philadelphia: John Benjamins Publishing Company.

Sweetser, Eve \& Gilles Fauconnier. 1996. Cognitive links and domains: basic aspects of mental space theory. In Eve Sweetser \& Gilles Fauconnier (eds.), Spaces, worlds, and grammar, 1-28. Chicago: The University of Chicago Press.

Turner, Mark \& Gilles Fauconnier. 1995. Conceptual integration and formal expression. Metaphor and Symbolic Activity 10 (3). 183-203.

Wierzbicka, Anna. 1992. Semantics, Culture and Cognition. Oxford: Oxford University Press 
Wierzbicka, Anna. 2003/1991. Cross-Cultural Pragmatics. The Semantics of Human Interaction. $2^{\text {nd }}$ ed. Berlin: Mouton de Gruyter.

Wierzbicka, Anna. 2006. English. Meaning and Culture. Oxford: Oxford University Press.

Wierzbicka, Anna. 2010. Cross-cultural communication and miscommunication: the role of cultural keywords. Intercultural Pragmatics 7 (1). 1-23.

Yu, Ning. 2018. LIFE as OPERA. A Cultural Metaphor in Chinese. In Sharifian, Farzad (eds.), Advances in cultural linguistics, 65-87. Singapore: Springer. DOI: 10.1007/978-981-104056-6 4.

\section{Словари и электронные ресуры / Dictionaries and Internet Resources}

Новый Большой англо-русский словарь: в 3 т. Под общ. рук. Э.М. Медниковой и Ю.Д. Апресяна. Москва: Русский язык, 1993.

\section{Список источников эмрпирического материала/ Empirical Material Resources}

Atwood, Margaret. 1981. Bodily Harm. Toronto: Seal Books.

Atwood, Margaret. 1982. Lady Oracle. London: Virago Press.

Atwood, Margaret. 1988. Great Unexpectations In Van Spanckeren and Castro (ed.) Margaret Atwood. Vision and Form. Carbondale and Edwardville: Southern Illinois University Press, xii - xvi.

Brodsky, Joseph. 2005. Watermark. St. Petersburg: Azbooka Publishing House.

Bryson, Bill. 1998. Notes from a Small Island. London: Black Swan.

Buchan, Elizabeth. 2002. Revenge of the Middle-Aged Woman. London: Penguin Books.

Buchan, Elizabeth. 2010. Wives Behaving Badly. London: Penguin Books.

Coetzee, John Michael. 1980. Waiting for the Barbarians. London: Penguin Books.

Coetzee, John Michael. 2000. Disgrace. London: Penguin Books.

Coetzee, John Michael. 2010. Summertime: Scenes from Provincial Life. London: Vintage Books.

Forsyth, Frederick. 2003. Avenger. London: Gorgi Books.

Fry, Stephen. 1997. The Liar. London: Arrow Books.

George, Elizabeth. 2009. Careless in Red. London: Hoddr \& Stoughton.

Gail, Honeyman. 2017. Eleanor Oliphant is Completely Fine. London: Harper Cillins Publishers

Hosseini, Khaled. 2003.The Kite Runner. New York: Riverhead Books.

Hosseini, Khaled. 2008. A Thousand Splendid Suns. New York: Riverhead Books.

Hosseini, Khaled. 2013. And the Mountains Echoed. New York: Riverhead Books.

Ishiguro, Kazuo. 1982. A Pale View of Hills. London: Faber \& Faber Limited.

Ishiguro, Kazuo. 1986. An Artist of the Floating World. London: Faber \& Faber Limited.

Ishiguro, Kazuo. 2000. When We were Orphans. London: Faber \& Faber Limited.

Kinsella, Sophie. 2006. The Undomestic Goddess. London: Black Swan.

Lindberg, Anne Morrow. 1955. A Gift from the Sea. New York: Pantheon Books.

Mayle, Peter. 1991. A Year in Provence. New York: Vintage Books.

Mayle, Peter. 2000. Encore Provence. London: Penguin Books.

Mayle, Peter. 2004. A Good Year. New York: Alfred A.Knopf.

McEwan, Ian. 2007. Atonement. London, Vintage Books.

Moyes, Jojo. 2005. The Ship of Brides. London: Hodder \& Stoughton.

Murdoch, Iris. 1975. A Word Child. London: Chato \& Windus.

Murdoch, Iris. 1978. The Sea, The Sea. London: Penguin Books. 
Nabokov, Vladimir. 1990. Pnin In Vladimir Nabokov. Selected Prose and Verse. Moscow: Raduga Publishers.

Ozeki, Ruth. 2013. A Tale for the Time Being. Edinburgh - London: Canongate.

Roberts, Gregory David. 2004. Shantaram. London: Abacus.

Tan, Amy. 1989. The Joy Luck Club. New York: G.P. Putnam's Sons.

Tan, Amy. 2006. The Kitchen God's Wife. London: Penguin Books.

\section{Article history:}

Received: 30 June 2020

Revised: 15 October 2020

Accepted: 17 October 2020

\section{История статьи:}

Дата поступления в редакцию: 30 июня 2020

Дата принятия к печати: 17 октября 2020

\section{Bionote:}

Lyubov KOZLOVA is Doctor of Philology (Advanced Doctorate), Professor at Altai State Pedagogical University. Her research interests embrace cognitive semantics, ethnolinguistics, intercultural communication, and comparative typology.

\section{Contact information:}

Altai State Pedagogical University.

55 Molodyezhnaya street, Barnaul, Russia, 656031

e-mail:1yubovkozlova@list.ru

ORCID ID: 0000-0002-0247-3843

\section{Сведения об авторе:}

Любовь Александровна КОЗЛОВА - доктор филологических наук, профессор кафедры английской филологии Алтайского государственного педагогического университета. Сфера научных интересов: когнитивная семантика, этнолингвистика, межкультурная коммуникация, сравнительная типология.

\section{Контактная информация:}

Алтайский государственный педагогический университет

656031, г. Барнаул, ул. Молодежная, д. 55

e-mail: lyubovkozlova@list.ru

ORCID ID: 0000-0002-0247-3843 